$\mathbb{T}$ Periodica Polytechnica Social and Management Sciences

25(2), pp. 97-107, 2017

https://doi.org/10.3311/PPso.9657

Creative Commons Attribution (1)

RESEARCH ARTICLE

\section{Role of Mental Complexity and Personality in Leadership}

\author{
Rita Répáczki ${ }^{*}$, Márta Juhász¹, Krum Krumov ${ }^{2}$
}

Received 25 June 2016; accepted after revision 23 August 2016

\begin{abstract}
In the world of organizations, the role of leaders is particularly important, considering that their personalities, behaviour and performance characteristics are relevant not only from their own point of view, but also for the development of the staff and the processes of the whole organization. The 21st century has brought changes and new challenges in the everyday life of employees, and these new challenges are especially noticeable in the business sector and in the lives of leaders. The aim of this study was to explore how mental complexity and personality characteristics are related to attitudes and thinking about leadership. Another goal was to develop a quantitative method for testing mental complexity. In order to assess our hypotheses we applied a quantitative research method $(N=358)$ and used a Mental Complexity Questionnaire (27 items, 3 scales: Social Complexity Scale, Individual Complexity Scale and Inter-Individual Complexity Scale) (Répáczki, 2014).
\end{abstract}

\section{Keywords}

mental complexity, meaning making, leadership, personality, Mental Complexity Questionnaire

\footnotetext{
${ }^{1}$ Department of Ergonomics and Psychology, Faculty of Economic and Social Sciences, Budapest University of Technology and Economics, H-1521 Budapest, Hungary

${ }^{2}$ University of Finance, Business and Entrepreneurship, Bulgaria

*Corresponding author, e-mail: repaczkirita@erg.bme.hu
}

\section{Introduction}

The changes of the 21 st century have increased the complexity of the whole world and especially the labour market. The demands placed on leaders are also changing constantly. The emergence of the Internet, the development of information technology and the growth of the digital world have brought significant changes to our daily lives, and these changes are especially noticeable in the world of work. Leaders are in an extraordinary position; a leader must plan, think and act more intensively than an average worker, so a leader's thinking and cognitive characteristics are related to his efficacy and to the success of the whole organization.

These effects are intensified in the innovation-based business world, which operates with a special tempo and rhythm due to the intense competition, frequent technological advances and rapidly changing landscape. In an innovation-based environment it is impossible to keep up without the ability to adapt quickly. Under these circumstances, successful organizations are those whose leaders have the cognitive and emotional capacities required to rapidly transform themselves and the whole company.

In order to be able to handle the diversity, complexity and high tempo of the contemporary business environment, a leader must have appropriate cognitive and emotional capacities. To keep pace with these changes, a leader should go beyond the mere "exchange" view of leader-subordinate relationship, and must accept that something more must be provided if he wants to be effective in the leader role. This new type of leader must be a role model for subordinates, someone who motivates them and inspires loyalty. Such leaders are characterized by very deep inner conviction and deep belief in certain ideals and principles which they apply in management practice. These principles are regularly reviewed and questioned, and they will reject or modify principles which do not stand up to testing. A leader, who possesses these qualities, must have mature intellectual, emotional and social functions. These properties are usually not congenital, but can be developed as a part of the maturation process during development. Mature and credible leaders are special in terms of meaning making and in their level of 
mental complexity. Different levels of mental complexity produce different types of leadership attitude, thinking and modes of operation, and mental complexity is also determinative in the management practices of the leader.

Previously, mental complexity was typically examined using qualitative methods. The most widely used method is SubjectObject Interview (SOI), developed by Lahey et al. (1988). Using this methodology (Répáczki, 2014) we found that its application is difficult and cumbersome, and it is not really practical in the business and economics sector. For this reason, we developed a quantitative methodology for testing mental complexity. As a result of this process a Mental Complexity Questionnaire with 27 items was created that is appropriate for testing the three typical adult dimensions of mental complexity separately.

Based on mental complexity and personality, in our research we examined how people think of an "ideal leader"; and we aimed to explore what kind of leadership types can be separated in terms of mental complexity and personality.

\section{Changes to the 21st Century Labour Market}

Complexity, change, innovation, rapid reactions - these are the main characteristics of the present day business and economic environment. The conditions around us are changing quickly, dynamically and in a complex way, so rapid response and quick adaptation are needed to stay effective and competitive. Due to the internet and the development of the virtual sphere this effect is expected to be stronger in the near future and it is becoming a part of our everyday life.

Complexity and Globalization. The world of work and the nature of work tasks are becoming increasingly complex. Multifunctionality is expected nowadays in most positions, while previously a job required a relatively narrow range of skills. This means that a worker should possess a range of competences. Furthermore, the growing number of international projects leads to interaction between people from diverse cultures and between more varied types of people, and this increased complexity which must be managed by leaders with an open mind (Frese, 2000).

Change and Innovation. Changes arrive rapidly and fast adaptation is a requirement and a key for success. Innovation means creating something new or unusual, not only at an intellectual or theoretical level - good ideas must be workable and implementable (Kanter, 1984).

Immediacy and Internet. A continuous online presence and access is evident today, and information can be shared and commented on immediately. Individuals want to live in the "here and now", and want to be answered immediately after sharing a question or a topic (Wallace, 2004). This phenomenon is evident in both life and work alike, although problems in the world of work tend to be more complex. The internet can help meet this demand for immediacy, even if the problem cannot be defined well.
Work, Career, Space and Time. While formerly "work" was defined by working hours and the work place, today it is characterized by tasks, activities or projects. Working individuals can work almost anywhere if the appropriate technology (internet, smart phones, tablets, laptops, PDAs, Blackberries) is available. Modern information and communications tools allow not only constant access to information, but also to continuously maintain staff relations (Répáczki and Juhász, 2012). Career questions challenge the individual and self-management is now essential, with career management seen as mainly an individual responsibility (Kiss and Répáczki, 2012).

Four Generations on the Labour Market. The world of work shows unprecedented diversity, with employees of both sexes and various nationalities and age groups working together. Four active generations are present on the labour market: Veterans, Baby Boomers, Generation $\mathrm{X}$ and Generation $\mathrm{Y}$. All of them have unique specialties in knowledge, skills and competence. Together they constitute the resource which has the highest value for an organization: the specialized human value. Generational researchers define and characterize various generations by their socioeconomical effects, socialization background and common experience, and in terms of the influences forming the specificities, personal characteristics, values and habits of a given age group. Most workplaces are a multigenerational environments and the cooperation of different generational cohorts is vital.

\section{Changing Expectations of Leadership}

\subsection{Leaders' Mental Complexity}

The diversity, complexity and high tempo of contemporary work environments require effective leaders to possess rapid case detection capabilities to adapt quickly, and to constantly strive for new opportunities. All this is impossible without strong cognitive and emotional capacities. Classical leadership concepts and practice are insufficient to keep up with these changes; leaders must provide more. (New Leadership Paradigm; Bryman, 1992). Leaders with these characteristics can become role models, and inspire people to follow them and to make a commitment. They are characterized by their deep inner conviction and firm belief in certain ideas and principles. They regularly review and question their principles and accept them only if they withstand this testing process repeatedly. They are able to present an inspiring vision and motivate innovation and teamwork (Bryman, 1992). Such a mature leader has more complex meaning making ability and special mental complexity structure, and to reach such a level of maturity, a leader must go through several stages of developmental process and experience. The development of mental complexity and meaning making means that the individual is able to understand more and more aspects of the world around him/her, and is able to interiorize more features of the world to gain more control and the ability to formulate principles of one's own (Kegan, 1982). 


\subsection{Reinterpreting the Leadership Role}

In Kegan's conception (1980) the key to efficacy is meaning making (mental) complexity, which determines how quickly and effectively an individual can understand and manage environmental challenges. Mental complexity is related to leadership maturity; the higher the level of mental complexity the more the individual can understand the environment around him. An individual with a higher level of mental complexity can understand people who operate on lower levels of mental complexity, which results in a necessary asymmetry between the parties (Day and Halpin, 2003). According to Avolio and Gibbons (1989) a leader who is on a lower maturity level in mental complexity than his subordinates will not be able to understand and help them in the developmental process.

\section{Development of Mental Complexity and Meaning Making}

During the development of mental complexity, the individual understands more and more about the world around him, and makes it a part of his own system. During this process one gains control, becomes abler to formulate one's own principles, and learns how to adapt. For the developmental process to evolve certain environmental impacts are needed, which an already established cognitive system can be tested by. This review process ensures a genuine commitment to the actual meaning making system; and without this constant process of questioning the individual would not be able to reach higher levels of mental complexity (Kegan, 1982).

Development is a transformational process, which can be divided in stages. The development process shows a spiral movement, so an individual cannot regress. The actual complexity of meaning making is based on "subject", "object" and their relationship to each other. Subject is unquestioned, simply a part of the self, that can never be seen as it is a part of the individual. Object consists of "those elements of our knowing or organizing that we can reflect on, handle, look at, be responsible for, relate to each other, take control of, internalize, assimilate, or otherwise operate upon" (Kegan, 1994, p. 32). During development the thing that was subject on a certain level, becomes object on the next. More objects mean more complex meaning making process which is why Kegan's (1982) theory is called meaning making (mental complexity) theory.

Three levels are associated with adulthood: Socialized Mind (third level), Self-actualizing Mind (fourth level) and Self-transforming Mind (fifth level). All of these levels represent a radically different interpretation of the world around. The differences are qualitative and well recognized (Kegan, 1980; Kegan, 1982).

\subsection{Description of Social Complexity Level and Mode}

In the Third Order, at the Socialized Mind (Social Complexity) level, people can internalize others' perspectives and care about others' opinions. The motivation for doing things is "because it's the right thing to do, it is expected" even if it is not in one's self-interest. Kegan describes this meaning-making structure as "Traditionalist" as it includes an internalized sense of mutual reciprocity in social relationships. On this level "others" are very important for the individual; one is guided by the norms and standards of others.

\subsection{Description of Individual Complexity Level and Mode}

In the Fourth Order, at the Self-actualizing (Individual Complexity) level the individual can handle values, assumptions and ideas in a more complex way. He is able to examine different rule-systems, opinions, and expectations; and is able to mediate among them using an internal set of rules and regulations. This self-governing system allows the individual to choose or decide, to have goals, strategies and the ability to analyse. Incoming information passes through the particular filter of the individual on this level and relevant information can be understood more easily and quickly.

\subsection{Description of Inter-individual Complexity Level and Mode}

At the Fourth Order, an individual can take a perspective on externally imposed values and expectations but cannot see how his own personal system is limited by historical, cultural, psychological, personal, and other forces. Such an understanding is gained at the Fifth Order. At the self-transforming (Interindividual Complexity) level the individual also has a "filter", but it becomes an object on the fifth level. The individual evaluates and classifies events that happen around him and is aware that the world is permanently changing: anything that is obvious today can become something different tomorrow. Incoming information is relevant to question the adequacy of the current level of mental complexity; and one evaluates all the information.

\section{Mental Complexity and Meaning Making in Leadership}

McCauley et al. (2006) applied Kegan's theory specifically for interpreting managerial effectiveness, and examined three issues: a) the influences of mental complexity level on management efficacy; b) the influences of subordinates' mental complexity level on their assessment of their leader's behaviour; c) special features of the environment enabling leaders' mental complexity to develop. Van Velsor and Drath (2004) found that challenging leadership situations are personal and depend on an individual's mental complexity. For a manager on the Social complexity level an ill-defined leadership role is a real challenge, as is a minority position within the group. For a manager on the Social complexity level it is difficult to understand and help colleagues who are on the Individual or Inter-individual 
complexity levels, so it is more comfortable for the leader to have subordinates with lower complexity levels.

\section{Role of Personality}

According to Judge et al. (2002), the Big Five factors are significantly related to the operation of leaders. The "effective leadership" profile developed by them can be described by low Neuroticism, while Extraversion, Consciousness and Openness to experience factors correlate positively with it. Agreeableness is not a significant factor in effective leadership; kindness is not a typical determining characteristic of good leaders (Barrick and Mount, 1993).

Extraversion is the strongest personality factor in effective leadership. A leader needs to appear to be dynamic, active and dominant (Hogan, Curphy and Hogan, 1994). Extraversion primarily predicts the possibility of "becoming a leader", because individuals with high Extraversion are more competent in social situations, and thus others perceive them as leaders. The "openness to experience" factor is needed in leadership for divergent and creative thinking. Neuroticism correlates negatively with self-confidence and self-esteem. Consciousness shows a closer relationship with the "becoming leader" process than with leadership efficacy, because conscious individuals seem, thanks to their good organizing skills, to be leaders. Agreeableness does not seem to be an important factor in leadership, because agreeable people are usually tagged as collaborative and passive, which are not real leadership characteristics (Bass, 1990).

\section{Aim of the study}

The 21 st century has brought business, economical, technical and labour market changes. Innovation, self-management, personal responsibility and self-direction are essential skills for anyone who strives to live a meaningful life. Considering organizational and work psychological processes, a leader is a key person, whose actual state and relative maturity influences subordinates and the processes they manage. We assume that complexity of meaning making correlates with a leader's attitude to leadership and that mental complexity can be explored as it applies to different types of individuals. The attitude of the leader in terms of mental complexity is not the only determining factor of successful leadership. The role of personality cannot be neglected either, because it influences leadership in several ways. Based on the Five Factor Model, our goal is to discover how personality profile can develop in parallel with mental complexity. Our aim is to separate mental complexity profiles that determine clusters with different personality characteristics and attitudes toward leadership.

\section{Hypothesises}

\subsection{Hypothesis Related to the Interaction between Mental Complexity and Personal Characteristics}

Mental complexity and personality are determining factors in leadership. These two constructs influence the leadership process both separately and by their interaction. The focus of our first hypothesis was the relationship between mental complexity and personality; we tried to explore and explain their relationship and its specialties (Strang and Kuhnert, 2009).

Hypothesis 1: Scales of Mental COMPLEXITy AND SCALES OF PERSONALITY CORRELATE WITH EACH OTHER.

We expected that Social Complexity would correlate positively with Extraversion, Agreeableness, Consciousness, Neuroticism; and negatively with Openness to experience. Individual Complexity was expected to correlate positively with Consciousness, Openness to experience; negatively with Neuroticism; and its correlation with Extraversion and Agreeableness would not be significant. Inter-individual Complexity was expected to correlate positively with Extraversion, Agreeableness, Consciousness, and Openness to experience; negatively with Neuroticism.

\subsection{Hypothesis Related to the Interaction between Mental Complexity and Thinking about Leadership}

In the literature of mental complexity and leadership, it is a relevant question, what kind of leadership role can be identified with different levels of mental complexity. In modern leadership theories, the leadership role has an entirely new interpretation. Besides task-oriented factors developmental aspects of leadership role are also emphasized: innovation, staff development, cooperation and teamwork are defined as essential leadership competencies. In our model, individuals with high mental complexity identify with modern leadership conception.

Hypothesis 2: A Socialized Mind CAN Be identified WITH a TRADITIONAL LEADERSHIP CONCEPTION, SO SOCIAL COMPLEXITY WILL NEGATIVELY CORRELATE WITH THE VARIABLES OF The 'Ideal Leadership' ToOl; Self-ACtUalizing AND SELF-TRANSFORMING INDIVIDUALS CAN BE IDENTIFIED WITH MODERN LEADERSHIP CONCEPTION, SO INDIVIDUAL AND INTERINDIVIDUAL COMPLEXITY WILL POSITIVELY CORRELATE WITH VARIABLES OF THE 'IDEAL LEADERShIP' TOOL.

\subsection{Hypothesis Related to the Interaction between Mental Complexity, Personal Characteristics and Thinking about Leadership}

The way of thinking about leadership is determined by mental complexity, personality and the interaction of the two. The following hypotheses are related to this conception. 
Hypothesis 3: The variables of 'IDEAL LeadershiP' ARE PREDICTED BY THE VARIABLES OF MENTAL COMPLEXITY AND PERSONALITY.

Hypothesis 4: In OUR SAMPLE WE CAN DISTINGUISH MENTAL Complexity Profiles (Clusters). There are remarkable DIFFERENCES BETWEEN THE CLUSTERS IN PERSONALITY CHARACTERISTICS AND THINKING ABOUT 'IDEAL LEADERSHIP'.

\section{Sample and Method}

9.1 Sample

The main target group of the research was Generation Y, the young adult generation of the present labour market. The mental complexity of the entire sample was measured, and independent from the currently occupied (leadership) status we explored relationships and drew conclusions. Our sample was heterogenic in terms of both work experience and labour market sector.

353 individuals took part in the research. Age. Their average age was 28.07 years (SD (Standard Deviation)=7.148) (minimum 18, maximum 40). We divided the whole sample into age groups: 1st group - 18-25 years old members; 2nd group - 26-30 years old members; 3rd group - 31-35 years old members; 4th group - 36-40 years old members. Gender. There were 155 males (44\%) and 198 females (56\%) in the sample. The males' average age was 25.27 years $(\mathrm{SD}=6.07)$ (minimum 18, maximum 40); females average age was 30.26 years $(\mathrm{SD}=7.178)$ (minimum 18, maximum 40). Education. There were 110 (23\%) individuals in the first group with secondary education and 243 (69\%) individuals with higher level education. Work experience. The sample was separated into four groups: (a) without experience (49 people; 13.9\%); (b) 1-3 years' experience (123 people; 34.8\%); (c) 4-10 years' experience (74 people; 21\%); (d) more than 10 years' experience (107 people; 30.3\%). The average work experience of the sample was 2.68 years $(\mathrm{SD}=1.05)$. Sector (type of workplace). The sample was divided into four groups. $33.4 \%$ of the sample (118 people) has no workplace; $37.1 \%$ of the sample (131 people) works in the public sector; $25.5 \%$ of the sample (90 people) works in the private sector; $4 \%$ of the sample (14 people) works in the non-profit sector. Leadership. $43.3 \%$ of the sample (153 people) has leadership experience. 200 people $(56.7 \%)$ have no leadership experience; 86 people $(24.4 \%)$ have 1-3 years' leadership experience; 55 people (15.6\%) have 4-10 years' leadership experience; 12 people (3.4\%) have more than 10 years' leadership experience. Currently held position. $118(33.1 \%)$ people are not in employment at the time of the data collection. 137 people (38.8\%) were subordinates; 50 people $(14.2 \%)$ lead smaller teams (with a maximum number of 5 members); 49 people (13.9\%) lead larger teams (with a minimum number of 5 members).

\subsection{Method}

Data collection was managed online in the first quarter of 2014. Part of the sample was contacted through Economics, Management and MBA courses of BUTE (Budapest University of Technology and Economics), others were contacted directly by contacts with employers.

\subsection{Research tools}

A classical questionnaire-based survey was carried out using closed questions and lists of characteristics. After collecting socio-demographic data, mental complexity, personality and thinking about leadership were tested.

\subsubsection{Socio-demographical data}

The survey was conducted anonymously, but respondents had an opportunity to ask for personal feedback on the results obtained. We collected data related to gender, age, education, work experience and managerial experience.

\subsubsection{Mental Complexity Questionnaire}

For information about mental complexity we used the 3 scales of Mental Complexity Questionnaire (MCQ), which was developed in an earlier phase of the same research (Répáczki, 2014). The MCQ Questionnaire contains 27 statements about characteristics of the three adult modes of mental complexity. Individuals rated items on a five-point Likert scale (1: Not typical of me; 2: Not really typical of me; 3 : Sometimes typical of me, sometimes not; 4: Fairly typical of me, 5: Very typical of me). The questionnaire has three scales: a Social Complexity Scale (M (Mean) =23.6; SD=6.95; Cronbach Alpha $=0,92)$, an Individual Complexity Scale $(M=34.9$; $\mathrm{SD}=6.95$; Cronbach Alpha $=0,81$ ), and an Inter-individual Complexity Scale $(\mathrm{M}=32.6 ; \mathrm{SD}=5.8$; Cronbach Alpha=0,83). The scale score is the sum of the items' score on the certain scale; a higher score indicates that the specified characteristics are more typical of the individual.

Three scales and the 27 items of the questionnaire can be seen in Table 1.

\subsubsection{Big Five Inventory}

The main focus of the research was not personality testing, so we needed a particularly short tool for measuring personality. We used the Big Five Inventory (John and Srivastava, 1999; Soto and John, 2009), which was calibrated on a Hungarian sample (Rózsa et al, in preparation). The questionnaire contains 44 items, all of which have to be evaluated on a five-point Likert scale (1: Do not agree, 2: Don't really agree, 3: Both agree and disagree, 4: Somewhat agree, 5: Completely agree). The scale point is the average of the item points assessed on a given scale. The BFI has five scales: Extraversion (Energy, positive emotions, surgency, assertiveness, sociability and talkativeness.), 
Neuroticism (The tendency to experience unpleasant emotions easily, such as anger, anxiety, depression, and vulnerability.), Agreeableness (A tendency to be compassionate and cooperative rather than suspicious and antagonistic towards others.), Consciousness (A tendency to be organized and dependable, show self-discipline, act dutifully, aim for achievement, and prefer planned rather than spontaneous behaviour.) and Openness to experience (Appreciation for art, emotion, adventure, unusual ideas, curiosity, and variety of experience. Openness reflects the degree of intellectual curiosity, creativity and a preference for novelty and variety.) (Costa and McCrae, 1985).

\subsection{4 "Ideal Leadership" Questionnaire}

This questionnaire was developed by our research team in 2014 (Répáczki, 2014). Items were drawn up along modern principles of leadership (Bryman, 1992; Joiner és Josephs, 2007; Kegan and Lahey, 1984) and general management tasks (Kotter, 1999). After the data collection we re-evaluated the dimensions of the questionnaire so that the revised version contained 6 scales and 49 items, and can be used for evaluation of thinking about leadership.

Task Orientation. This scale includes a range of items related to the ideal leader's task orientation: his focus on task management, deadlines, work and the performance of team members. $(\mathrm{M}=16.3 ; \mathrm{SD}=3.67)$.

Cooperation. This scale describes a leader's preferences regarding team work: is he a team player? Can he pay attention to involving subordinates in the work of the team? $(\mathrm{M}=21.7$; $\mathrm{SD}=2.53$ ).

People Orientation. This scale describes whether relationship management and the well-being of team members is important to the leader. People orientation means openness to human processes while Cooperation denotes the efficacy of team processes. $(\mathrm{M}=19.6 ; \mathrm{SD}=3.12)$.

Innovation. These items relate to the importance for an ideal leader of developing people and processes, and of seeking out and resolving mistakes and problems. An innovative leader is creative and open to change. $(\mathrm{M}=16.6 ; \mathrm{SD}=2.32)$.

Responsibility. This scale describes the extent to which the leader feels responsible for processes, people and management of development. This scale also indicates whether the leader is motivated to gather and share information, and to stay informed of the progress of processes, and is motivated to stay abreast of initiatives and pick up tips related to the team and the organization. ( $\mathrm{M}=17.1 ; \mathrm{SD}=2.08)$.

Authenticity. These items relate to the extent to which the ideal leader accepts and embraces himself, and does not want to present a contrived image. He takes responsibility for his opinions, ideas and thoughts, and does not attempt to hide his mistakes. $(\mathrm{M}=13 ; \mathrm{SD}=1.79)$.
Table 1 Scales and items of Mental Complexity Questionnaire

\begin{tabular}{l}
\hline \multicolumn{1}{c}{ Mental Complexity Questionnaire } \\
\hline I would rather choose a routine situation instead of a new and \\
unknown one. \\
I mainly enjoy constant situations. \\
I do not change if it is not absolutely necessary. \\
I enjoy usual and familiar circumstances. \\
I avoid changes if I can. \\
I avoid new and unknown situations. \\
Changes make me feel uncertain because I do not know what is \\
coming afterwards. \\
I stick to established routines. \\
I do not mind if there is no challenge in my everyday life.
\end{tabular}
Individual Complexity Scale

The most important thing for me is to be able to stay true to my principles.

I want to meet my own expectations.

In an uncertain situation I stick to my own principles.

I believe that I have to follow my own goals, which I have set for myself.

The most important thing for me is to be able to live according to my own principles while respecting those of others.

In a decision making situation I form my own opinion and choose an option that I can commit myself to.

Primarily I want to accommodate to my own norms.

People have to find their own way by a self-managed process.

Everybody has to find their way to self-development on his/her own.

Inter-individual Complexity Scale

I help others to find their own way to self-development.

I like tasks that make me develop while I help others to develop themselves.

If someone cannot keep up with the team, I help him.

I like tasks which give me the opportunity to help others.

Real success for me is to help enable my team to achieve common success.

I enjoy making sacrifices to help others.

I like talking to people if it helps them.

I enjoy working as part of a team.

I prefer to work together as a team.

\section{Research Results}

Data were analyzed with SPSS for Windows 19.0 statistical software. 
Table 2 Correlations of Social Complexity and personality characteristics

\begin{tabular}{llllll}
\hline & Extraversion & Agreeableness & Consciousness & Neuroticism & Openess to Experience \\
\hline $\begin{array}{l}\text { Social Complexity } \\
\text { Pearson r }\end{array}$ & -.439 & -.151 & -.187 & .276 & -.450 \\
$\begin{array}{l}\text { Level of } \\
\text { significance }\end{array}$ & .000 & .005 & .000 & .000 & .000 \\
\hline
\end{tabular}

Table 3 Correlations of Individual Complexity and personality characteristics

\begin{tabular}{llllll}
\hline & Extraversion & Agreeableness & Consciousness & Neuroticism & Openess to Experience \\
\hline $\begin{array}{l}\text { Inter-Individual } \\
\text { Complexity Pearson } \mathrm{r}\end{array}$ & .060 & .019 & .158 & -.020 & .222 \\
Level of significance & .261 & .719 & .003 & .715 & .000 \\
\hline
\end{tabular}

Table 4 Correlations of Inter-individual Complexity and personality characteristics

\begin{tabular}{llllll}
\hline & Extraversion & Agreeableness & Consciousness & Neuroticism & Openess to Experience \\
\hline $\begin{array}{l}\text { Individual Complexity } \\
\text { Pearson } \mathrm{r}\end{array}$ & .432 & .616 & .181 & -.198 & .347 \\
\begin{tabular}{l} 
Level of significance \\
\hline
\end{tabular} & .000 & .000 & .001 & .000 & .000 \\
\hline
\end{tabular}

Table 5 Correlations of Social Complexity and leadership specialties

\begin{tabular}{llllll}
\hline & Task Orientation & Cooperation & People Orientation & Innovation & Responsibility \\
\hline $\begin{array}{l}\text { Social Complexity } \\
\text { Pearson } \mathrm{r}\end{array}$ & -.071 & -.204 & -.181 & -.416 & -.144 \\
Level of significance & .185 & .000 & .001 & .000 & .007 \\
\hline
\end{tabular}

\subsection{Results Related to the Interaction between Mental Complexity and Personal Characteristics}

Social Complexity shows a strong negative correlation with Extraversion $(\mathrm{r}=-0.44 ; \mathrm{p}<0.001)$, and a poor, but also negative correlation with Agreeableness $(\mathrm{r}=-0.15 ; \mathrm{p}=0.005)$ and Consciousness $(\mathrm{r}=-0.19 ; \mathrm{p}<0.001)$. Its correlation with Neuroticism is positive and significant $(r=0.27 ; \mathrm{p}<0.001)$; and its correlation with Openness to experience is strong and negative $(\mathrm{r}=-0.45 ; \mathrm{p}<0.001)$. See correlations of Social Complexity and personality characteristics in Table 2.

Individual Complexity shows significant correlation with Consciousness $(\mathrm{r}=0.16 ; \mathrm{p}=0.003)$ and Openness to experience $(r=0.22 ; p<0.001)$. These correlations are positive but not strong. Individual Complexity shows weak but positive correlation with Extraversion ( $\mathrm{r}=0.06 ; \mathrm{p}=0.261)$ and Agreeableness $(\mathrm{r}=0.02 ; \mathrm{p}=0.719) ;$ and shows negative correlation with Neuroticism $(r=-0.20 ; p=0.715)$. See correlations of Individual Complexity and personality characteristics in Table 3 .

Inter-individual Complexity shows a strong positive correlation with Extraversion ( $\mathrm{r}=0.43 ; \mathrm{p}<0.001)$, Agreeableness $(\mathrm{r}=0.61 ; \mathrm{p}<0.001)$ and Openness to experience $(\mathrm{r}=0.35$; $\mathrm{p}<0.001)$. Its correlation with Neuroticism $(\mathrm{r}=-0.20 ; \mathrm{p}<0.001)$ and Consciousness $(\mathrm{r}=0.18 ; \mathrm{p}=0.001)$ seem to be significant but weak. See correlations of Inter-individual Complexity and personality characteristics in Table 4 .

Mental complexity and personality variables showed correlations in several cases and the first hypothesis was partially verified.

\subsection{Results Related to the Interaction between Mental Complexity and Thinking about Leadership}

Social Complexity shows a significant strong and negative correlation with Innovation $(\mathrm{r}=-0.42 ; \mathrm{p}<0.001)$ and a significant but weak correlation with Cooperation $(r=-0.20 ; p<0.001)$, People Orientation ( $\mathrm{r}=-0.18 ; \mathrm{p}=0.001)$, Responsibility $(\mathrm{r}=-$ $0.14 ; \mathrm{p}=0.007)$ and Authenticity $(\mathrm{r}=-0.15 ; \mathrm{p}=0.003)$. The correlation between Social Complexity and Task Orientation is not significant $(\mathrm{r}=-0.07 ; \mathrm{p}=0.19)$. The correlation of the Social Complexity scale with modern leadership specialties is negative. See correlations of Social Complexity and leadership specialties in Table 5 .

Individual Complexity shows a strong positive correlation with People Orientation ( $\mathrm{r}=0.36 ; \mathrm{p}<0.001)$, Responsibility $(\mathrm{r}=0.34 ; \mathrm{p}<0.001)$ and Authenticity $(\mathrm{r}=0.33 ; \mathrm{p}<0.001)$. 
Table 6 Correlations of Individual Complexity and leadership specialties

\begin{tabular}{lllllll}
\hline & Task Orientation & Cooperation & People Orientation & Innovation & Responsibility & Authenticity \\
\hline $\begin{array}{l}\text { Individual Complexity } \\
\text { Pearson } \mathrm{r}\end{array}$ & .197 & .259 & .360 & .261 & .344 & .327 \\
\begin{tabular}{l} 
Level of significance \\
\hline
\end{tabular} & .000 & .000 & .000 & .000 & .000 & .000 \\
\hline
\end{tabular}

Table 7 Correlations of Inter-individual Complexity and leadership specialties

\begin{tabular}{lllllll}
\hline & Task Orientation & Cooperation & People Orientation & Innovation & Responsibility & Authenticity \\
\hline $\begin{array}{l}\text { Inter-individual } \\
\text { Complexity Pearson } \mathrm{r}\end{array}$ & .120 & .333 & .312 & .297 & .215 & .214 \\
Level of significance & .024 & .000 & .000 & .000 & .000 & .000 \\
\hline
\end{tabular}

Its correlation with Task Orientation is significant, but not strong $(\mathrm{r}=0.20 ; \mathrm{p}<0.001)$, as are the correlations with Cooperation $(\mathrm{r}=0.26 ; \mathrm{p}<0.001)$ and Innovation $(\mathrm{r}=0.26 ; \mathrm{p}<0.001)$. See correlations of Individual Complexity and leadership specialties in Table 6.

Inter-individual Complexity shows a strong positive correlation with People Orientation $(\mathrm{r}=0.31 ; \mathrm{p}<0.001)$ and Cooperation $(r=0.33 ; \mathrm{p}<0.001)$. Its correlation with Innovation $(\mathrm{r}=0.29 ; \mathrm{p}<0.001)$, Responsibility $(\mathrm{r}=0.21 ; \mathrm{p}<0.001)$ and Authenticity $(r=0.21 ; \mathrm{p}<0.001)$ is significant but not strong. Its correlation with Task Orientation is significant but weak $(r=0.12 ; p=0.024)$. See correlations of Individual Complexity and leadership specialties in Table 7.

Negative correlations were identified between Social Complexity and leadership scales, suggesting that this level of mental complexity may be characterized by the presence of traditional leadership principles. Individual and Inter-Individual Complexity showed typically positive correlations with leadership scales, which suggest that these mental complexity modes may be associated with modern leadership principles. The second hypothesis was thus verified.

\subsection{Results Related to the Interaction between Mental Complexity, Personal Characteristics and Thinking about Leadership}

The constructs examined can explain $5.3 \%$ of the variance of Task Orientation. In the emergence of Task Orientation, only Individual Complexity and Consciousness seem to be significant (Individual Complexity $\beta=0.175$; Consciousness $\beta=0.141$; Adj. R2 $=0.053$ ) where both predict Task Orientation positively. Task-oriented individuals may be characterized by the importance they place on personal performance, and their belief in themselves (Individual Complexity), as well as their precise and accurate task management, and deadline-orientation (Consciousness). The weakness of the model suggests, however, that variance in Task Orientation is not primarily determined by the measured variables.
Four measured variables were considered to be significant in explaining the variance of Cooperation: Inter-individual Complexity, Individual Complexity, Social Complexity and Agreeableness. These constructs can explain $18.7 \%$ of the variance of Cooperation (Inter-individual Complexity $\beta=0.204$, Individual Complexity $\beta=0.245$, Social Complexity $\beta=-0.144$ and Agreeableness $\beta=0.128$; Adj. R2=0,187). Inter-individual Complexity, Individual Complexity and Agreeableness predict Cooperation positively, while Social Complexity predicts it negatively. Cooperation is about working together, thinking, acting with a team perspective and adding individual performance to team performance. Inter-individual complexity is one of the main features of team work and has a major impact on the results of a team. Social Complexity is associated with fear of change, so in our model a high level of Social Complexity predicts low levels of Cooperation. The role of Agreeableness is also comprehensible, since Agreeableness predicts supporting others and willingness of contribution to common results.

The following constructs can explain $26.1 \%$ of the variance of People Orientation (Individual Complexity $\beta=0.311$, Extraversion $\beta=0.154$, Inter-individual Complexity $\beta=0.193$ and Consciousness $\beta=0.162$; Adj. R2=0.261). A High Individual Complexity level is characterized by self-improvement, selfoperation and loyalty to oneself, principles which may also be a part of the individual's social life. Extraversion refers directly to 'social life' and preference for community events. Interindividual Complexity refers to 'team life' and the importance of common performance. Consciousness is also important in the model, because it can focus not only on tasks but also on people and relationships.

The variance in levels of Innovation can be explained by: Openness to experience, Social Complexity, Individual Complexity, Consciousness and Inter-Individual Complexity. These variables explain $34.1 \%$ of the variance of Innovation (Openness to experience $\beta=0.273$, Social Complexity $\beta=-0.248$, Individual Complexity $\beta=0.177$, Consciousness $\beta=0.127$, Interindividual Complexity $\beta=0.110$, Adj. R2=0.341). Innovation 
Table 8 Clusters converted by scales of Mental Complexity Questionnaire

\begin{tabular}{llll}
\hline & Cluster $1(\mathrm{~N}=155 ; 43.9 \%)$ & Cluster 2 $(\mathrm{N}=108 ; 30.6 \%)$ & Cluster 3 (N=90; 25.5\%) \\
\hline Inter-Individual Complexity & 35.44 (moderate) & 39.27 (high) & $28.62($ low) \\
SocialComplexity & 20.42 (low) & 28.11 (moderate) & 31.33 (high) \\
Individual Complexity & 34.17 (moderate) & 37.03 (moderate) & 34.69 (moderate) \\
\hline
\end{tabular}

relates to development and openness to new trends, while Openness to experience as a personality trait is about the importance of experience and improvement. The $\beta$ value of Social Complexity is negative, which is also meaningful, as Social Complexity is associated with anxiety of change: this contradicts Innovation. The importance of Consciousness in the model can also be understood as it is necessary for task management, while Inter-Individual Complexity is necessary for the model because of the importance of team-work in Innovation.

The variance of Responsibility can be explained by the following constructs: Individual Complexity, Consciousness, Inter-individual Complexity and Extraversion. These variables explain $20 \%$ of the variance of Responsibility (Individual Complexity $\beta=0.301$; Consciousness $\beta=0.183$; Inter-individual Complexity $\beta=0.111$; Extraversion $\beta=0.115$; Adj. R2=0,200). Individual Complexity can be characterized by autonomy and self-sufficiency. This is confirmed by Consciousness. Interindividual Complexity and Extraversion should be added to the model because of the social and team aspect of these variables.

The variance of Authenticity is explained by three examined variables, which explain $15.1 \%$ of the variance: Individual Complexity $\beta=0.318$; Inter-individual Complexity $\beta=0.161$; Social Complexity $\beta=-126 ;$ Adj. R2=0,151. Individual and Inter-individual complexity mode are characterized by independence, and people with high values of these variables accept themselves and behave accordingly. The $\beta$ value of Social Complexity is negative in this construct, meaning that the higher the individual's Social Complexity level, the less one can be characterized by an authentic operation mode.

Most of our assumptions related to the relationship between the examined constructs were largely confirmed, although the model of Task Orientation is really weak, suggesting that this variable cannot be predicted by the measured variables. It is promising, however, that the variables of 'thinking about ideal leadership can be explained to some degree by mental complexity and personality variables.

The third hypothesis was verified.

Based on the values which individuals achieved on the scales of the Mental Complexity Questionnaire we created clusters. We used two-step method. At first, hierarchical cluster analysis was performed by Ward method using a squared Euclidean distance. Based on the results of the hierarchical cluster analysis we checked three, four, and five clustered solutions. The results of hierarchical cluster analysis (by dendogram) indicated that a three-clustered solution was the most meaningful. The final cluster centre points were converted with the K-means (stepwise) method (see Table 8).

The values of the clusters can be seen below (Fig. 1).

The standardized centre points of the clusters can be seen in Fig. 2.

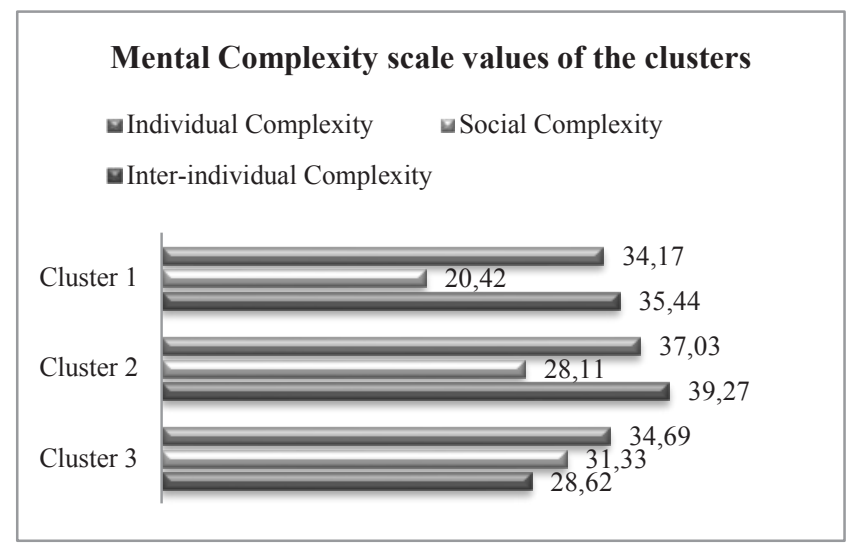

Fig. 1 Values of the clusters along Mental Complexity scales

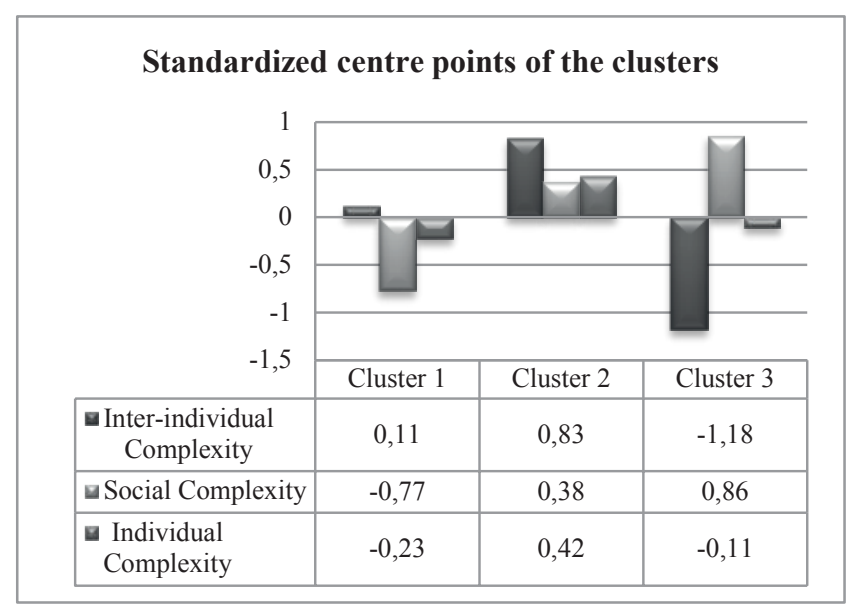

Fig. 2 Standardized centre points of the clusters

There are 155 persons in Cluster 1, comprising $43.9 \%$ of the sample. The average age of Cluster 1 is 27.95 years $(\mathrm{SD}=6.92)$ and the breakdown by gender was 70 males $(45.2 \%$ of the cluster) and 85 females (54.8\% of the cluster). 42 individuals (27.1\%) were educated only to secondary level and 113 individuals $(72.9 \%)$ had higher education. Individuals in this cluster can be characterized by moderate Inter-Individual Complexity (z-score $=0.11)$, low Social Complexity $(\mathrm{z}$-score=-0.77) and moderate Individual Complexity $(\mathrm{z}-\mathrm{score}=-0.23)$. This suggests that teamwork is less important to these people and solitary activities and work are preferred. They look for the 
possibilities for change, innovation and development, so this cluster was called 'initiative individualist'. An average level of Extraversion, Agreeableness and Consciousness are typical for this cluster. The values for Neuroticism are low and Openness to experience displays average values, while still higher than the Openness value of both the other groups. Based on the leadership variables this cluster shows average or high values, typically lower than the second but higher than the third cluster. The values of relationship-oriented leadership characteristics (Cooperation, People Orientation) are lower in this cluster than in Cluster 2. The value of the Innovation scale is high in their case, which indicates the importance of development to them.

There are 108 people in Cluster 2 which makes up $30.6 \%$ of the sample. The average age of Cluster 2 is 29.95 years $(\mathrm{SD}=7.40)$. There are 35 males (32.4\%) and 73 females $(67.6 \%)$ in this cluster. $23.1 \%$ of the cluster members ( 25 people) have secondary education, while $76.9 \%$ of the cluster members ( 83 people) have higher education. In this cluster, individuals can be characterized by high Inter-individual Complexity (z-score $=0.83$ ), moderate Social Complexity (z-score $=0.38$ ) and moderate Individual Complexity ( $\mathrm{z}$-score $=0.42$ ). These individuals prefer team work, and they appreciate the possibilities and strengths of the team. They believe that individual limitations can be well compensated by teamwork, where individuals can complement and help each other. Therefore, this cluster was called 'friendly team player'. Low Neuroticism, high Agreeableness, average Extraversion, average Openness to experience and average Consciousness are characteristic for them. Based on leadership variables this cluster achieved typically high values; they attained the highest values on the relationship-oriented scales: Cooperation and People orientation. Innovation, Responsibility and Authenticity are also typical of them.

There are 90 persons in Cluster 3 which forms $25.5 \%$ of the sample. The average age of Cluster 3 is 26.01 years $(\mathrm{SD}=6.70)$, and it is composed of 50 males $(55.6 \%)$ and 40 females $(44.4 \%)$ in this group. 43 people possess only secondary education, which is $47.8 \%$ of the sample, while 47 have completed higher education, making up $52.2 \%$ of the sample. The individuals in Cluster 3 can be characterized by their low Inter-individual Complexity (z-score=-1.18), high Social Complexity (z-score $=0.86)$ and moderate Individual Complexity (z-score=-0.11). People in this cluster prefer to act individually; they do not feel competent in team work. These people are wary of changes and try to avoid them. As they prefer familiar and well-tried circumstances and conditions, this cluster was called 'conservative performer'. Members of this cluster can be characterized by high Neuroticism, low Extraversion, Agreeableness and Openness to experience, and moderate values of Consciousness. The scales of 'thinking about ideal leadership' showed lower values, so these individuals have difficulty identifying themselves with modern leadership principles. In their case Task Orientation, Cooperation,
People Orientation, Innovation, Responsibility and Authenticity show low values.

We managed to isolate three stable clusters statistically using the scales of the Mental Complexity Questionnaire. These clusters differ from each other in personality traits and in terms of the variables of 'thinking about ideal leadership', so we can declare that Mental Complexity Profiles can be created along mental complexity specialties (see Fig. 3).

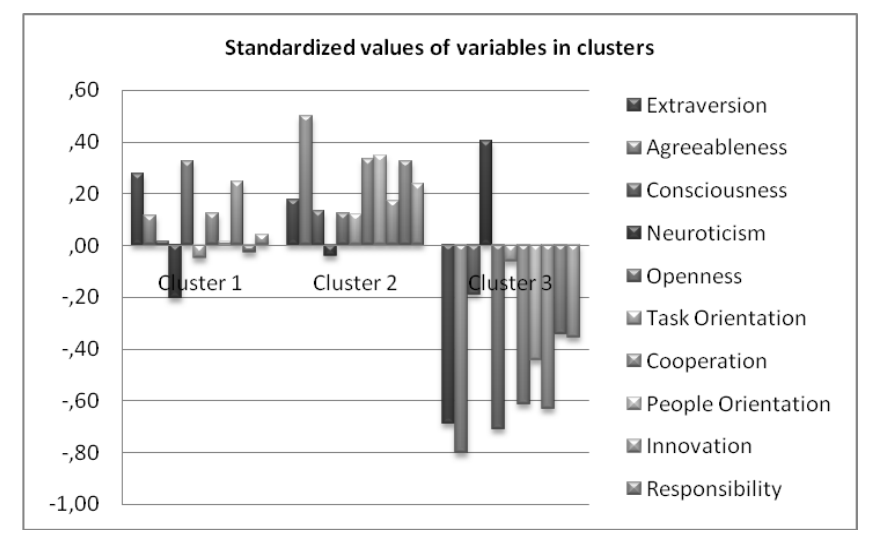

Fig. 3 Standardized values of variables in clusters

The Fourth hypothesis was verified.

\section{Conclusion}

In the last 20-30 years there have been numerous changes in the world of work. Technological development and the expansion of digital world have created circumstances that have changed expectations about human characteristics. As the role of leaders has been emphasized in the organizational processes, expectations related to the leadership role have changed dramatically. The features of "effective leadership" have changed also, and "effective" leadership has gained a new meaning.

The way individuals observe the world and think about events and developments is related to their cognitive development. During development the way individuals observe the world changes continuously, and with development their understanding of the world gradually expands. This developmental process correlates with age, but the experiences gained are also crucial determinants. The result of this process is general maturation and a growth in efficacy. In a leadership role the individual gains special experience, which makes this maturational and growing process special in its own way. Leadership identity and efficacy is related to these processes.

In our research we wanted to explore what type of profiles can be separated in terms of mental complexity. By revealing and investigating mental complexity and personality traits simultaneously, we explored attitudes and ways of thinking about "ideal leadership". As a result, we identified three broad attitudinal types (clusters): "initiative individualist", "friendly team player" and "conservative performer". Belonging to one cluster or another seemed to be informative about life 
management and work specialties, but it becomes especially relevant to leadership positions, mainly about leadership identity and preferred management practices. Mental complexity is a determining construct in the evolution of the leadership role and leadership efficacy. In our research mental complexity dimensions correlated with personality dimensions which together were able to predict variance of leadership variables. Based on cluster analysis, we separated mental complexity profiles, which differ from each other in personality and leadership characteristics. Specialties of "thinking about ideal leadership" are predicted by the cognitive and personality characteristics of the individual. We found that individuals with different mental complexity profiles can be characterized with different personality characteristics and attitudes to leadership.

\section{References}

Avolio, B., Gibbons, T. (1989). Developing transformational leaders: A life span approach. In: Charismatic Leadership: The Elusive Factor in Organizational Effectiveness. (Conger, J., Kanungo, R. (eds.)), JosseyBass, San Francisco. pp. 276-308.

Barrick M. R., Mount, M. K. (1991). The Big Five personality dimension and performance: a meta-analysis. Personnel Psychology. 44(1), pp. 1-26. https://doi.org/10.1111/j.1744-6570.1991.tb00688.x

Bass, B. M. (1990). From transactional to transformational leadership: learning to share the vision. Organisational Dynamics. 18(3), pp. 19-31. https://doi.org/10.1016/0090-2616(90)90061-S

Bowler, M. C., Bowler, J. L., Phillips, B. C. (2009). The Big-5 \pm 2 ? The impact of cognitive complexity on the factor structure of the five-factor model. Personality and Individual Differences. 47(8), pp. 979-984. https://doi.org/10.1016/j.paid.2009.08.002

Bryman, A. (1992). Charisma and leadership in organizations. Sage Publication, London.

Costa, P. T., McCrae, R. R. (1985). Revised NEO Personality Inventory (NEO$P I-R)$ and NEO Five-Factor Inventory (NEO-FFI) Professional Manual. Psychological Assessment Resources, Odessa, FL.

Day, D. V., Halpin, S. M. (2001). Leadership development: A review of industry best practices. (Technical Report No. 1111). U.S. Army Research Institute for the Behavioral and Social Sciences, Fort Leavenworth, KS.

Frese, M. (2000). The Changing Nature of Work. In: Introduction to Work and Organizational Psychology. (Chmiel, N. (ed.)), pp. 425-439. Blackwell Publlishers Ltd., Oxford. 2000.

Hogan, R. T., Curphy, G. J., Hogan, J. (1994). What we know about leadership: Effectiveness and personality. American Psychologist. 49(6), pp. 493504. https://doi.org/10.1037/0003-066X.49.6.493

Joiner, W. B., Josephs, S. A. (2007). Leadership agility: Five levels of mastery for anticipating and initiating change. Jossey-Bass, San Francisco. 2007.

Judge, T. A., Bono, J. E., Ilies, R., Gerhardt, M. W. (2002). Personality and leadership: A qualitative and quantitative review. Journal of Applied Psychology. 87(4), pp. 765-780.
Juhász, M., Répáczki, R. (2012). Projekt-teamek terjedése a Magyar szervezeti kultúrákban. (Spreading of project teams in Hungarian organizational cultures.) Munkaügyi Szemle. 56(1), pp. 19-25. (in Hungarian)

Kanter, R. M. (1984). Managing transitions in organizational culture: The case of participating management at Honeywell. In: Managing Organizational Transitions. (Kimberly, J. R., Quinn, R. E. (eds.)), pp. 195-217. Dow Jones-Irwin, Homewood, IL.

Kegan, R. (1980). Making meaning: The constructive-developmental approach to persons and practice. The Personnel and Guidance Journal. 58(5), pp. 373-380. https://doi.org/10.1002/j.2164-4918.1980.tb00416.x

Kegan, R. (1982). The evolving self: Problem and process in human development. Harvard University Press, Cambridge, MA.

Kegan, R. (1994). Over Our Heads: The Mental Demands of Modern Life. Harvard University Press, Cambridge, MA.

Kegan, R., Lahey, L. (1984). Adult leadership and adult development: A constructivist view. In: Leadership: Multidisciplinary Perspectives. (Kellerman, B. (ed.)) pp. 199-229. Prentice Hall: Englewood Cliffs, New Jersey.

Kiss, I., Répáczki, R. (2012). Új készségek és munkahelyek: a kompetencia megközelítésre épülő szolgáltatások szerepe a foglalkoztathatóság javításában. Munkaerőpiac-orientáltfelsőoktatás. Ötletek, beváltgyakorlatokaz „Új készségek és munkahelyek” nevü európai kezdeményezéshez. (New skills and jobs: the role of competence-based approach to improve employability services. Labour market-oriented higher education. Ideas, best practices in the European initiative called 'New Skills and Jobs'.) Tempus Foundation, Budapest.

Kotter, J. P. (1999). John Kotter on What Leaders Really Do? Harvard Business Review Book, USA.

Lahey, L., Souvaine, E., Kegan, R. Goodman, R., Felix, S. (1988). A guide to subject-obejct interview: Its administration and interpretation. Harvard University, Graduate School of Education, Laboratory of Human Development, Cambridge, Mass.

McCauley, C. D., Drath, W. H., Palus, C. J., O’Connor, P. M. G., Baker, B. A. (2006). The use of constructive-developmental theory to advance understanding of leadership. The Leadership Quarterly. 17(6), pp. 634-653. https://doi.org/10.1016/j.leaqua.2006.10.006

Répáczki, R. (2014). Emerging of professional and leadership identity in young adulthood. Emerging of leadership identity in view of mental complexity and personality at young adults. Doctoral (PhD.) Thesis. ELTE PPK, Budapest. 2014.

Rózsa et al. (prepared) A Big Five Inventory hazai alkalmazása során szerzett tapasztalatok. (Experience gained from national use of Big Five Inventory.) (in Hungarian)

Torbert, B. (2004). Action inquiry: The secret of timely and transforming leadership. Berrett-Kohler, San Francisco, CA.

Van Velsor, E. Drath, W. H. (2005). A lifelong developmental perspective on leader development. In: McCauley, C. D., Van Velsor, E. (eds.) (2005). The center for creative leadership handbook of leadership development. Jossey-Bass, San Francisco

Wallace, P. (2004). The internet in the workplace: How new technology is transforming work. Cambridge University Press, New York, NY. 